\title{
A clinical and radiological evaluation of the biceps femoris muscle transposition technique in the treatment of cranial cruciate ligament rupture in small breed dogs \\ İlker ŞEN ${ }^{1}$, Ümit KAYA ${ }^{2}$
}

${ }^{1}$ Department of Surgery, Faculty of Veterinary Medicine, Sivas Cumhuriyet University, 58140, Sivas/TURKEY

${ }^{2}$ Department of Surgery, Faculty of Veterinary Medicine, Ankara University, 06110, Ankara/TURKEY

Key Words:

cranial cruciate ligament

rupture

small breed dog

stifle

transposition

Received $\quad \cdot 06.02 .2020$

Accepted : 13.07 .2020

Published Online : 30.12 .2020

Article Code : 685923

Correspondence:

I. ŞEN

(ilkersenn@yandex.com)

\begin{abstract}
The aim of this study was to evaluate the clinical results of the use of biceps femoris muscle transposition in the treatment of cranial cruciate ligament rupture in small breed dogs, weighing $\leq 15$ kilograms, through evaluation of the long-term functional results of the extremity and the elimination of lameness originating from joint instability. The study group was formed of 14 dogs of 4 different small breed dogs, with a mean weight of 9.8 kilograms, determined with cranial cruciate ligament rupture. All the dogs were treated with the biceps femoris muscle transposition technique. Postoperative clinical and radiographic evaluations were made on days 10,30,60 and 90. In the clinical evaluation, the Illinois University Evaluation Scale was used, and in the radiographic evaluation, the Osteoarthritis Progression Scale. In conclusion, clinical and radiological evaluations were made of biceps femoris muscle transposition and the technique was observed to be successful in the treatment of cranial cruciate ligament rupture in small breed dogs below 15 kilograms in weight. In comparison with other treatment methods, this technique has been determined to be reliable with the advantages that it is less invasive, operation costs are lower, it can be easily applied in a shorter time and complication rates are low.
\end{abstract}

ORCID:

İ. SEN : 0000-0001-8288-4871

Ü. KAYA: 0000-0001-9869-9072

* This study summarized from first author's doctoral

thesis.

\section{INTRODUCTION}

Cranial cruciate ligament (CCL) lesions are the primary cause of lameness in the knee joint and degenerative joint diseases in dogs (1-3). Just as ligament damage may occur following trauma, it may also occur from progressive, adaptive and degenerative changes. According to previous studies, trauma-related CCL rupture occurs at the rate of only $20 \%$. In the formation of the lesion, it has been reported that chronic degenerative arthritis has a greater role in the limping observed (1, 4-9).

CCL lesions are seen in 3 clinical forms as acute, chronic or partial lesions (10). The clinical signs of acute CCL lesions emerge as lameness and pain, joint effusion-hemarthrosis associated with acute joint inflammation, and suspension of the affected extremity. If there is no meniscus lesion, the severity of lameness in small breed dogs, generally starts to decrease at 3-6 weeks after the lesion formation without any treatment intervention (11-13).

Animals with chronic CCL lesions may continue weightbearing on the affected extremity for longer periods. When the animal is seating, it shows a tendency to extend the affected extremity outwards. Dogs with chronic cruciate ligament rupture have progressively worse lameness with physical activity, and chronic lameness develops in association with degenerati- ve joint disease (DJD) $(12,14)$

When the CCL is partially damaged, it is extremely difficult to determine cranial instability because of the fibrosis formed. Initially, there is a moderate degree of lameness with exercise, which resolves with rest. This stage of the disease can last for several months. With continuation of the ligament tear, knee joint stability deteriorates and degenerative changes progress significantly. Lameness increases and does not recover with rest and continuous effusion is seen in the joint $(12,13)$.

Studies conducted to decrease the incidence of lesions and to improve the clinical results of these lesions have increased the number of surgical tehniques (Hulse et al. 1983). As a result of these studies, joint instability has been reduced and steps have been noted to minimise the formation of osteoarthritis (15).

When selecting the method to be used in the treatment of dogs with CCL rupture, subjects related to the treatment which must be considered include the age, breed and weight of the dog, the tendency to obesity, any pre-existing orthopaedic or medical problems and the owner's economic status (16).

According to some researchers, CCL ruptures in dogs weighing $<15 \mathrm{~kg}$ can generally recover without surgical intervention 
(13). However, as the healing period of conservative treatment is long, surgical treatment may be preferred over conservative treatment for CCL rupture in small breed dogs. Nevertheless, of the surgical procedures recommended for treatment, no specific procedure has been accepted as optimal $(16,17)$.

The aim of this clinical study was to evaluate the application of biceps femoris muscle transposition, which is known to be less invasive than other methods, in the treatment of CCL rupture, which is a frequently seen problem in small breed dogs weighing $\leq 15 \mathrm{~kg}$, through examination of the long-term functional healing of the affected extremity and elimination of lameness originating from joint instability, and evaluation of the radiological data, thereby determining the advantages and disadvantages of this technique.

\section{MATERIAL and METHODS}

The study group was formed of 14 dogs of small breeds, of varying age, gender and breed, which were brought to the clinic with the complaint of lameness and were diagnosed with CCL rupture as a result of clinical and radiological examinations (Table 1).
90, new bone formation (osteophytes, enthesiophytes) was examined in respect of osteoarthritis which could develop in 11 specific anatomic areas. These areas were defined as; 1 . Apical patella, 2. Basal patella, 3. Proximal of the trochlea ossis femoris, 4. Medial of the trochlea ossis femoris, 5. Lateral of the trochlea ossis femoris, 6. Condylus lateralis ossis femoris and epicondylus medialis femoris, 7. Condylus lateralis ossis femoris and epicondylus lateralis femoris, 8. Fossa intercondylaris femoris, 9. Medial tibial plateau, 10. Lateral tibial plateau, 11. Caudal tibial plateau.

The severity of lesions in each of these areas evaluated in the radiological examination was scored from 0-3, and these scores were evaluated by a physician to determine the presence and progression of osteoarthritis in the knee joint.

\section{Surgical Technique}

The skin incision was made by applying a craniolateral approach starting from the distal third of the femur and extending to the proximal third of the tibia. By dissecting the subcutaneous connective tissue, the aponeurosis of the biceps femoris muscle was revealed and was then separated from the

Table 1. Data of the dogs included in the study.

\begin{tabular}{|c|c|c|c|c|c|}
\hline Case No & Breed & Age (year) & Gender & Weight (kg) & Location of Lesion \\
\hline 1 & Terrier (S) & 8 & $q$ & 9 & Right Stifle Joint \\
\hline 2 & Terrier & 1,5 & $\hat{o}$ & 10 & Right Stifle Joint \\
\hline 3 & Terrier & 1 & $\hat{\sigma}$ & 8,4 & Right Stifle Joint \\
\hline 4 & Jack Russell Terrier & 1 & $\hat{0}$ & 9 & Left Stifle Joint \\
\hline 5 & Terrier & 2 & $\hat{o}$ & 7 & Right Stifle Joint \\
\hline 6 & Terrier $(S)$ & 12 & q & 11 & Left Stifle Joint \\
\hline 7 & Terrier & 8 & $\sigma^{\lambda}$ & 9 & Left Stifle Joint \\
\hline 8 & Terrier & 6 & $\hat{0}$ & 9,6 & Left Stifle Joint \\
\hline 9 & Beagle & 5 & q & 14,2 & Right Stifle Joint \\
\hline 10 & Terrier (S) & 7 & $\hat{\sigma}$ & 10,1 & Left Stifle Joint \\
\hline 11 & Terrier & 1,5 & $\widehat{0}$ & 10,2 & Left Stifle Joint \\
\hline 12 & Terrier $(\mathrm{S})$ & 9 & q & 8 & Right Stifle Joint \\
\hline 13 & Pinscher & 6 & $\widehat{0}$ & 4,3 & Left Stifle Joint \\
\hline 14 & Beagle & 6 & $q$ & 12 & Left Stifle Joint \\
\hline
\end{tabular}

\section{Evaluation Protocol}

Following routine clinical and radiological examinations, the findings of lameness and knee joint pain were evaluated by two physicians using the Illinois University Evaluation Scale preoperatively and at 10,30,60 and 90 days postoperatively (Table 2).

On radiographs taken of the knee joint of the dogs in the $\mathrm{L} / \mathrm{L}$ (knee joint at $90^{\circ}$ in tibial compression) and $\mathrm{A} / \mathrm{P}$ positions (Innomed TOP-X HF, 2-tube x-ray machine) preoperatively and on days $10,30,60$, and 90 postoperatively, the long-term radiological results of the biceps femoris muscle transposition technique were evaluated.

In the radiographic evaluation made on postoperative day fascia lata. This procedure was followed by identification of the cranial insertion of the biceps femoris muscle.

An incision was made from the insertion attachment of the biceps femoris muscle and dissection was made towards 4-5 $\mathrm{cm}$ proximal from the underlying tissues. A triangular-shaped flap was prepared from this separated insertion, with the cranial margin of the biceps femoris muscle on one side separated from the caudal margin of the vastus lateralis muscle with a 3 $\mathrm{cm}$ incision, and on the other side, a $2-3 \mathrm{~cm}$ incision was made along the muscle fibrils to the caudal section of the distal of the biceps femoris muscle (Figure 1).

The flap formed was removed upwards and traction force was gradually applied in the cranial-medial-caudal direction. 


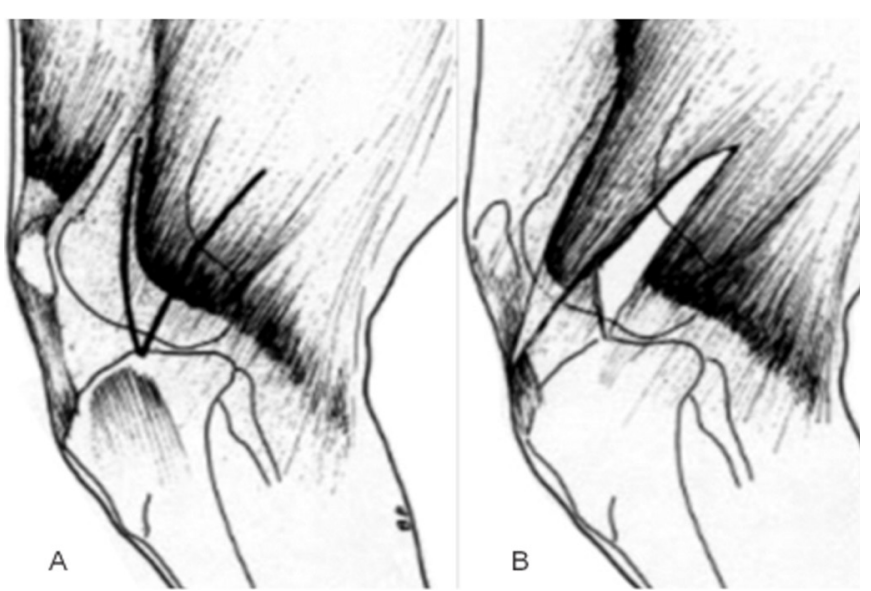

Figure 1. Flap preparation stages. A) Identification of the cranial insertion of the biceps femoris muscle. B) Flap formed from the biceps femoris muscle (17).

With the knee joint in extension, transposition of the flap was carefully made towards the tibia. The transposition of the biceps femoris muscle was made at the closest possible point to the attachment of the patella ligament to the tibial tuberosity, and was then sutured with 2-0 monofilament non-absorbable polypropylene suture thread (Prolene ${ }^{\circledR}$, Ethicon). The incision made along the muscle fibrils of the biceps femoris muscle was sutured with 2-0 monofilament absorbable polyglecaprone 25 (Monocryl ${ }^{\circledR}$, Ethicon) (Figure 2).

Cranial translation of the tibia was evaluated intraoperatively by applying the cranial drawer test to the operated joint. In cases with continuing cranial drawer movement despite
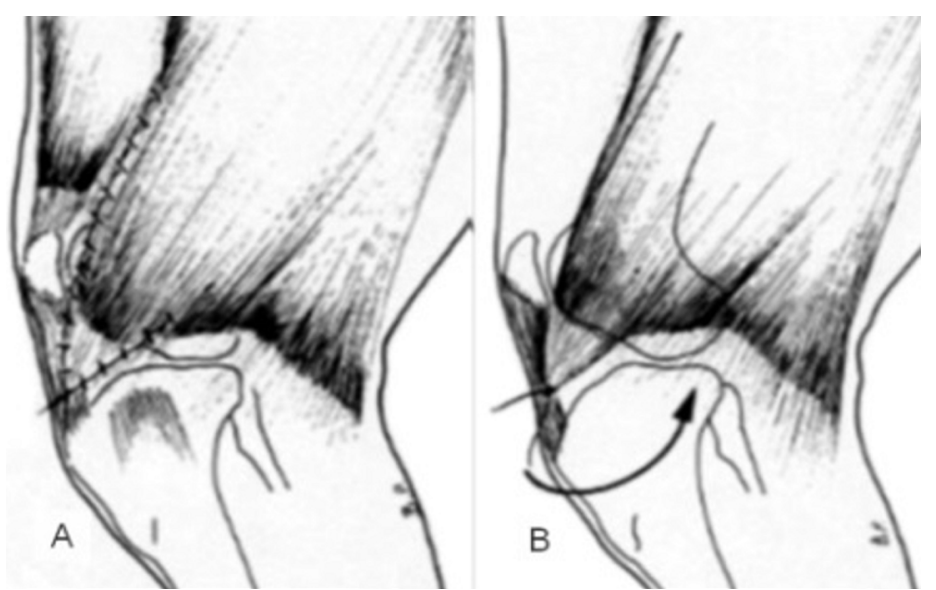

Figure 2. Stages of flap transposition. A) Suturing the flap to the patella ligament. B) Active force of the flap applied over the tibia postoperatively (17).

bandage was removed, wound healing in the operation area was checked and the sutures were removed.

\section{RESULTS}

\section{Preoperative Clinical Findings}

Following the clinical examination including the cranial drawer test and tibial compression test, and the mediolateral radiographs taken by applying tibial compression, the degree of lameness in the cases determined with CCL lesion and pain levels by moving the affected extremity into flexion and extension while lying laterally, were evaluated using the Illinois University Evaluation Scale (Table 2).

Table 2. The clinical evaluation of the study cases made on preoperative period using the Illinois University Evaluation Scale.

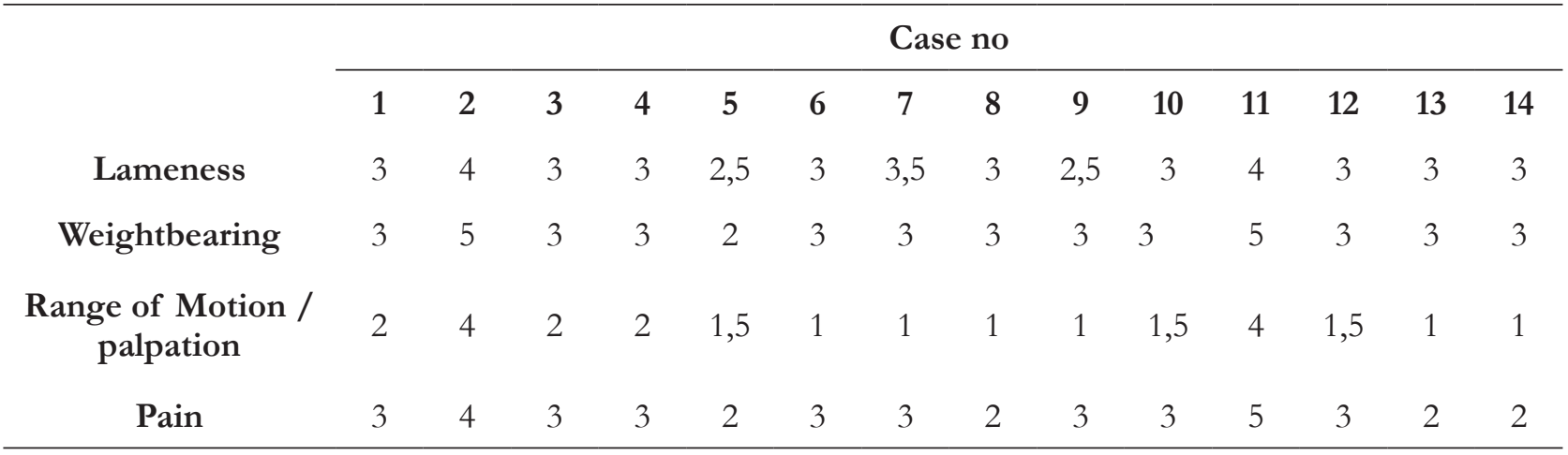

transposition, it was attempted to prevent cranial movement by increasing the tension of the biceps femoris muscle flap. No arthrotomy or arthrosynthesis was applied to any case. The operated area was routinely closed with sutures.

\section{Postoperative Medical Treatment and Bandage Application}

Postoperative analgesia was provided with meloxicam $0.3 \mathrm{mg} / \mathrm{kg}$ (Anaflex®, Hektaş, Turkey) administered via SC. All the dogs were administered $25 \mathrm{mg} / \mathrm{kg}$ oral amoxicillin clavulanic acid (Amoksilav BID, Ilsan, Turkey) for 7 days as antibiotherapy. The owners of the dogs were informed that the operated extremity must be protected for 10 days with the soft bandage (Robert-Jones) applied, and the dog's movements should be restricted for 15 days. On postoperative day 10, the

\section{Postoperative Clinical Findings}

A soft bandage was applied to all the cases for 10 days postoperatively. All the dogs tolerated the bandage well, and the bandage was seen to have protected the affected extremity. After 10 days the bandage was removed by the physician. No dressing or operation wound complications were observed in any of the cases.

The preoperative scoring applied according to the Illinois University Evaluation Scale was repeated on postoperative days 10, 30, 60, and 90 (Table 3). The data obtained according to the scale were evaluated statistically (Table 4).

According to the preoperative evaluation made with the Illinois University Evaluation Scale, the mean score for lameness 
Table 3. The clinical evaluation of the study cases made on postoperative days 10, 30, 60 and 90 using the Illinois University Evaluation Scale.

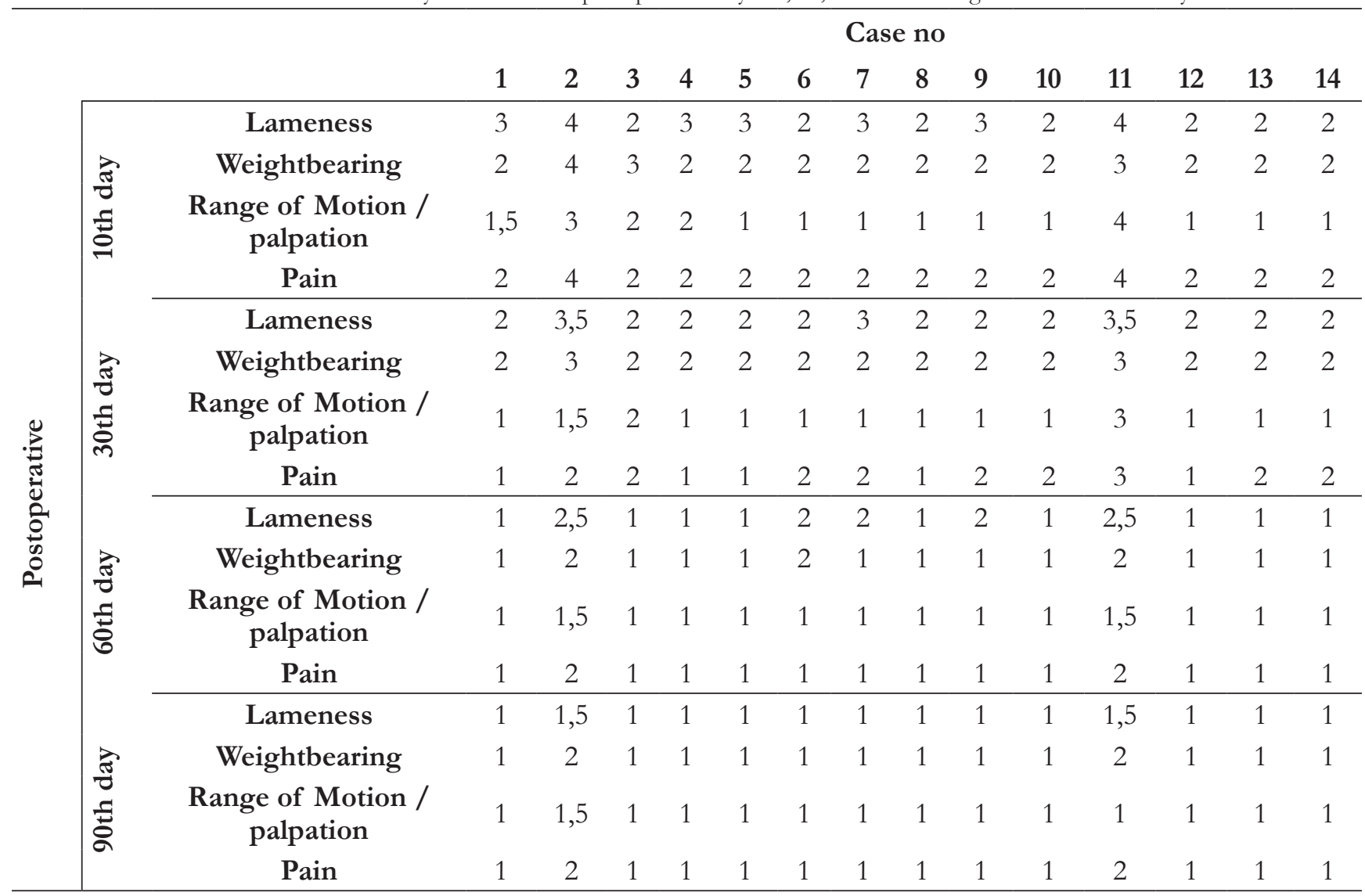

was 3.1, weightbearing on the affected extremity was 3.21, stifle joint range of motion 1.75 , and pain 2.93. At the evaluation made on postoperative day 90 , the mean points obtained for these parameters were 1.14, 1.14, 1.04 and 1.14, respectively.

To test the significance of change over time of the measurements taken for each variable, Friedman analysis was applied, and for variables with a significant difference, the Dunn-Bonferroni test was applied as post-hoc analysis. The data obtained were analysed statistically using SPSS vn 14.01 software and a value of $\mathrm{p}<0.05$ was accepted as statistically significant.

When the data obtained from the Illinois University Evaluation Scale were evaluated statistically, for the evaluation scale related to lameness, it was determined that while findings of lameness continued throughout days 0-60, a positive improvement was recorded in that time. In the scale related to weightbearing on the affected extremity, while the data obtained from days 0-30 were not significant, a statistically significant improvement was determined in the period after 30 days. In the scale related to knee joint range of movement and palpation, a statistically significant improvement was determined in the period of 60-90 days compared with the period of 0-60 days. In the scale related to pain evaluation, statistically significant positive differences were determined in the data from 0-10 days, from 10 -30 days and 30-60 days, and the improvement in the period of 60-90 days was reflected in the statistical data (Table 4).

\section{Postoperative Radiographic Findings}

All the cases were followed up clinically and radiographical- ly until the 90th postoperative day, and findings of osteoarthritis were investigated in 11 different areas of the knee joint. Factors of the thickness, density, and number of points of osteophyte formation were taken into consideration, and each area was scored from $1-3$, with 0 points given if there was no osteophyte formation. As a result of the osteoarthritis scoring (Table 5), no osteophyte formation was determined in cases 2 , 3 , 4, and 10. Cases 1, 5, 6, 7, 8, 9, 11, 12, and 13 obtained points of 1-4, and osteoarthritis-related changes were determined to be minimal. In case 14 , points obtained were in the range of 5-10, and non-severe degenerative changes were observed.

The preoperative M/L, postoperative 10 and 90-day postoperative M/L radiographs of case no.3 are shown in Figure 3.

The preoperative $\mathrm{M} / \mathrm{L}$ and 90 -day postoperative $\mathrm{M} / \mathrm{L}$ radiographs of case no. 7 are shown in Figure 4.

The preoperative $\mathrm{M} / \mathrm{L}, 10$-day postoperative standing, and 90-day M/L radiographs of case no.9 are shown in Figure 5. 
Table 4. Statistical Evaluations of the data obtained according to the Illinois University Evaluation Scale. The different letters $(\mathrm{a}, \mathrm{b}, \mathrm{c})$ in the median column represent a staistically significant difference. n: number of cases, p: error rate.

\begin{tabular}{|c|c|c|c|c|c|}
\hline & Postop. & $\mathrm{n}$ & $\underset{\text { deviation }}{\text { Arithmetic mean }} \pm$ Std. & Median (Min- Max) & $\mathrm{p}$ \\
\hline \multirow{5}{*}{ 苞 } & $0^{\text {th }}$ day & 14 & $3,11 \pm 0,45$ & $3(2,5-4)^{a}$ & $<0,05$ \\
\hline & $10^{\text {th }}$ day & 14 & $2,29 \pm 0,16$ & $2,5(2-4)^{a}$ & $<0,05$ \\
\hline & $30^{\text {th }}$ day & 14 & $2,14 \pm 0,10$ & $2(2-3,5)^{a}$ & $<0,05$ \\
\hline & $60^{\text {th }}$ day & 14 & $1,21 \pm 0,11$ & $1(1-2,5)^{a b}$ & $<0,05$ \\
\hline & $90^{\text {th }}$ day & 14 & $1,14 \pm 0,10$ & $1(1-1,5)^{b}$ & $<0,05$ \\
\hline \multirow{5}{*}{ 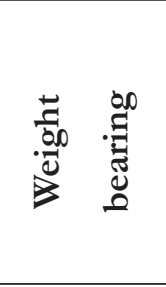 } & $0^{\text {th }}$ day & 14 & $3,21 \pm 0,21$ & $3(2-5)^{a}$ & $<0,05$ \\
\hline & $10^{\text {th }}$ day & 14 & $2,29 \pm 0,16$ & $2(2-4)^{a}$ & $<0,05$ \\
\hline & $30^{\text {th }}$ day & 14 & $2,14 \pm 0,10$ & $2(2-3)^{a}$ & $<0,05$ \\
\hline & $60^{\text {th }}$ day & 14 & $1,21 \pm 0,11$ & $1(1-2)^{b}$ & $<0,05$ \\
\hline & $90^{\text {th }}$ day & 14 & $1,14 \pm 0,10$ & $1(1-2)^{\mathrm{b}}$ & $<0,05$ \\
\hline \multirow{5}{*}{ 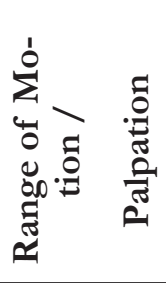 } & $0^{\text {th }}$ day & 14 & $2,93 \pm 0,83$ & $3(2-5)^{a}$ & $<0,05$ \\
\hline & $10^{\text {th }}$ day & 14 & $2,29 \pm 0,73$ & $2(2-4)^{a b}$ & $<0,05$ \\
\hline & $30^{\text {th }}$ day & 14 & $1,71 \pm 0,61$ & $2(1-3)^{\mathrm{bc}}$ & $<0,05$ \\
\hline & $60^{\text {th }}$ day & 14 & $1,14 \pm 0,36$ & $1(1-2)^{\mathrm{c}}$ & $<0,05$ \\
\hline & $90^{\text {th }}$ day & 14 & $1,14 \pm 0,36$ & $1(1-2)^{\mathrm{c}}$ & $<0,05$ \\
\hline \multirow{5}{*}{$\mathfrak{\Xi}$} & $0^{\text {th }}$ day & 14 & $1,75 \pm 0,28$ & $3(2-5)^{a}$ & $<0,05$ \\
\hline & $10^{\text {th }}$ day & 14 & $1,53 \pm 0,25$ & $2(2-4)^{a}$ & $<0,05$ \\
\hline & $30^{\text {th }}$ day & 14 & $1,25 \pm 0,16$ & $2(2-3)^{a}$ & $<0,05$ \\
\hline & $60^{\text {th }}$ day & 14 & $1,07 \pm 0,05$ & $1(1-2)^{\mathrm{ab}}$ & $<0,05$ \\
\hline & $90^{\text {th }}$ day & 14 & $1,04 \pm 0,04$ & $1(1-2)^{b}$ & $<0,05$ \\
\hline
\end{tabular}

Table 5. Osteoarthritis scoring of the cases on postoperative day 90.

\begin{tabular}{ccccccccccccc}
\hline $\begin{array}{c}\text { Case } \\
\text { No }\end{array}$ & $\mathbf{A}$ & $\mathbf{B}$ & $\mathbf{C}$ & $\mathbf{D}$ & $\mathbf{E}$ & $\mathbf{F}$ & $\mathbf{G}$ & $\mathbf{H}$ & $\mathbf{I}$ & $\mathbf{J}$ & $\mathbf{K}$ & Total \\
\hline $\mathbf{1}$ & 0 & 0 & 0 & 0 & 0 & 0 & 0 & 0 & 0 & 0 & 1 & 1 \\
$\mathbf{2}$ & 0 & 0 & 0 & 0 & 0 & 0 & 0 & 0 & 0 & 0 & 0 & 0 \\
$\mathbf{3}$ & 0 & 0 & 0 & 0 & 0 & 0 & 0 & 0 & 0 & 0 & 0 & 0 \\
$\mathbf{4}$ & 0 & 0 & 0 & 0 & 0 & 0 & 0 & 0 & 0 & 0 & 0 & 0 \\
$\mathbf{5}$ & 0 & 0 & 0 & 0 & 0 & 0 & 0 & 1 & 0 & 0 & 0 & 1 \\
$\mathbf{6}$ & 0 & 1 & 1 & 0 & 0 & 0 & 0 & 0 & 0 & 0 & 1 & 3 \\
$\mathbf{7}$ & 0 & 0 & 0 & 0 & 0 & 0 & 0 & 0 & 1 & 0 & 0 & 1 \\
$\mathbf{8}$ & 0 & 0 & 0 & 0 & 0 & 0 & 0 & 0 & 1 & 0 & 0 & 1 \\
$\mathbf{9}$ & 1 & 0 & 0 & 0 & 0 & 0 & 1 & 0 & 0 & 0 & 0 & 2 \\
$\mathbf{1 0}$ & 0 & 0 & 0 & 0 & 0 & 0 & 0 & 0 & 0 & 0 & 0 & 0 \\
$\mathbf{1 1}$ & 0 & 1 & 0 & 0 & 0 & 0 & 0 & 0 & 0 & 0 & 1 & 2 \\
$\mathbf{1 2}$ & 0 & 0 & 0 & 0 & 0 & 0 & 0 & 0 & 1 & 0 & 0 & 1 \\
$\mathbf{1 3}$ & 0 & 1 & 0 & 0 & 0 & 0 & 0 & 0 & 0 & 0 & 0 & 1 \\
$\mathbf{1 4}$ & 1 & 1 & 1 & 0 & 1 & 1 & 1 & 0 & 0 & 1 & 0 & 7 \\
\hline
\end{tabular}

A. Apical patella, B. Basal patella, C. proximal of the trochlea ossis femoris, D. Medial of the trochlea ossis femoris, E. Lateral of the trochlea ossis femoris, F. Condylus lateralis ossis femoris and epicondylus medialis femoris, G. Condylus lateralis ossis femoris and epicondylus lateralis femoris, H. Fossa intercondylaris femoris, I. Medial tibial plateau, J. Lateral tibial plateau, K. Caudal tibial plateau. 


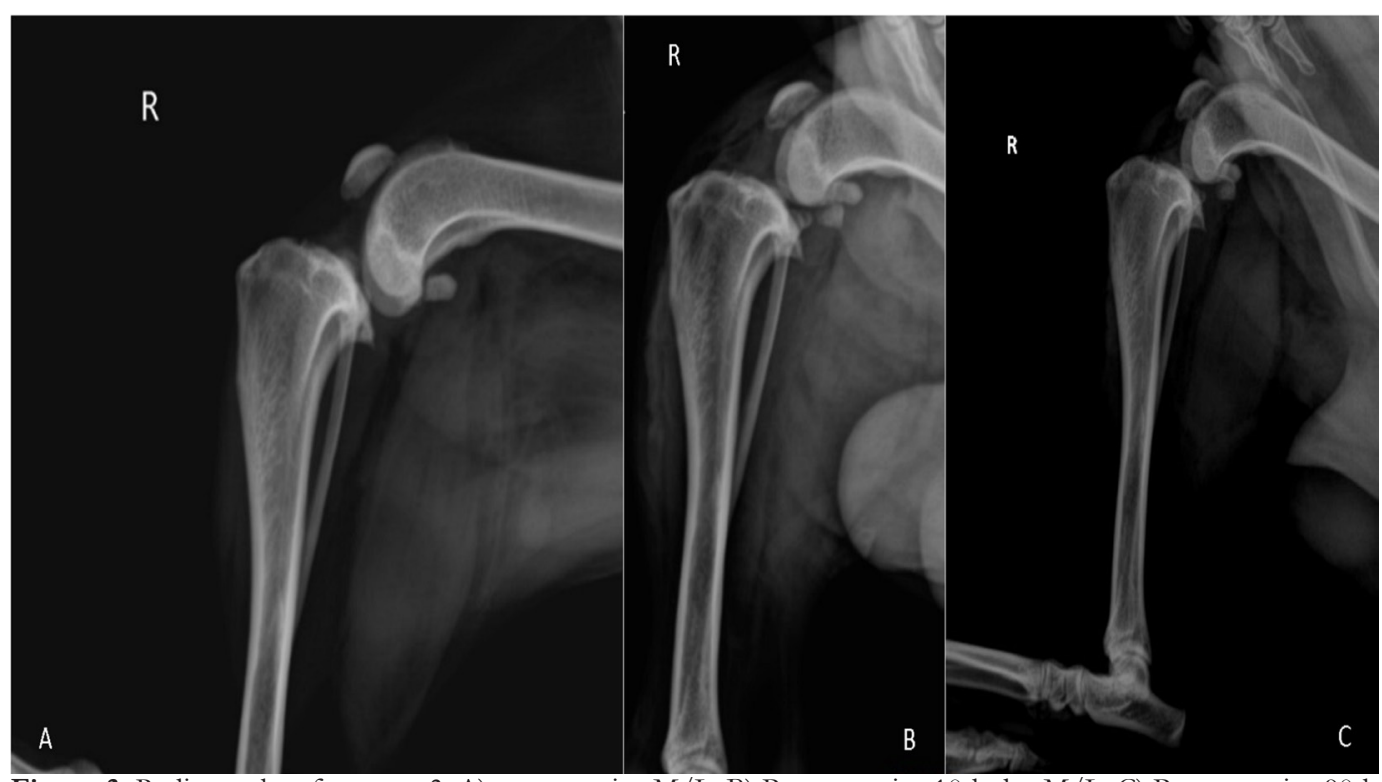

Figure 3. Radiographs of case no 3. A) preoperative M/L, B) Postoperative 10th day M/L, C) Postoperative 90th day $\mathrm{M} / \mathrm{L}$ radiographs.

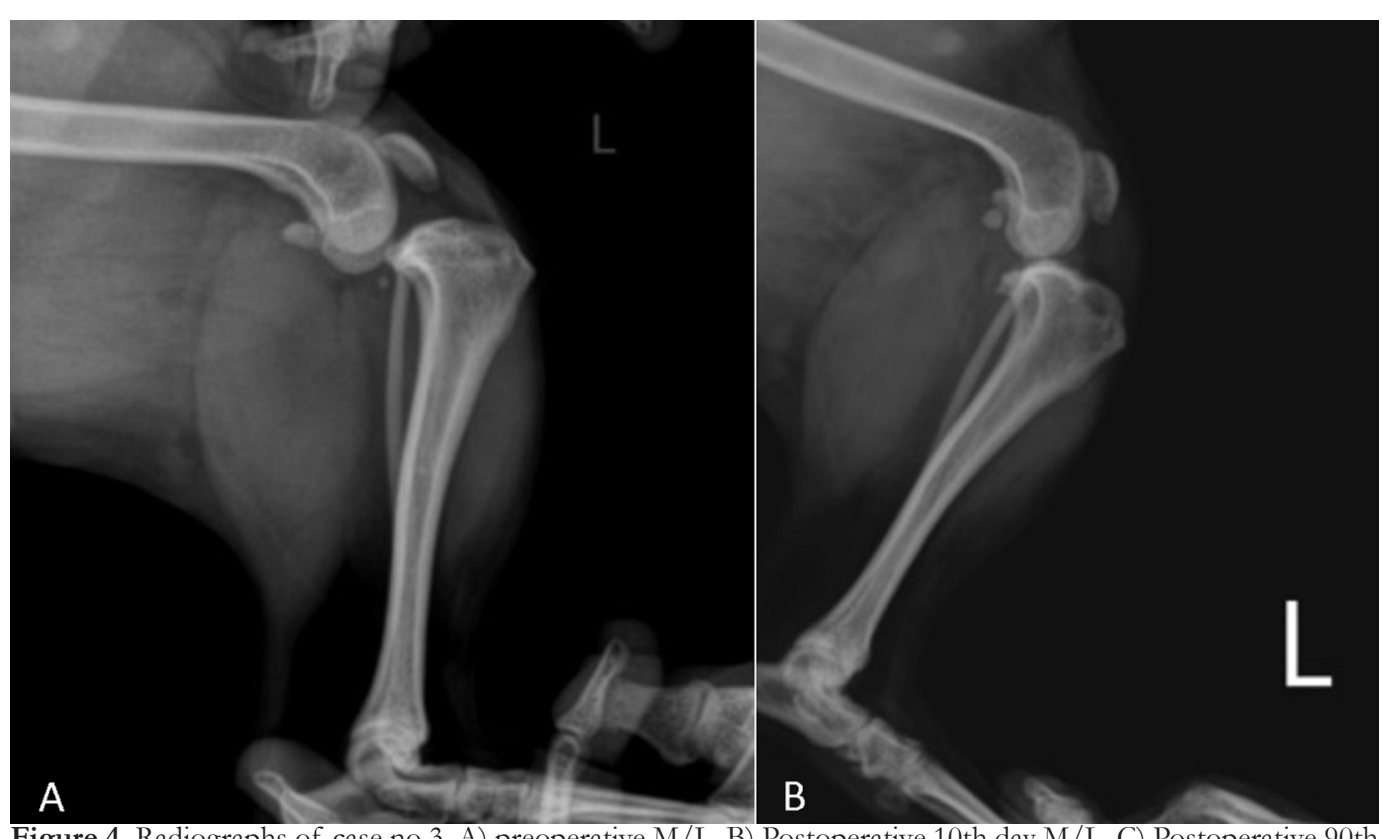

Figure 4. Radiographs of case no 3. A) preoperative M/L, B) Postoperative 10th day M/L, C) Postoperative 90th day $\mathrm{M} / \mathrm{L}$ radiographs.

\section{DISCUSSION}

With new techniques used in the treatment of CCL rupture in dogs, the satisfaction of dog owners has significantly increased despite the development of osteoarthritis in later periods. Although limping may be eliminated or reduced postoperatively in the extremity with CCL rupture, many dogs cannot apply full weightbearing on the affected extremity (18).

When clinically evaluating the biceps femoris muscle transposition technique in this study, the Illinois University Evaluation Scale was used. On postoperative day 10 , according to this scale, normal standing and severe limp when walking were determined in cases 1, 4, 5, 7 and 9, normal standing and mild limp when walking were determined in Cases $3,6,8,10,12,13$ and 14 , and defective standing and severe lameness when walking were determined in cases 2 and 11.In the evaluation of weightbearing on the affected extremity on postoperative day 10 , ab- normal weightbearing when standing and slight weightbearing when walking were determined in cases 1, 3 and 11, and normal weightbearing when standing with mild pressure on the affected extremity when walking in cases $4,5,6,7,8,9,10,12,13$, and 14. In case 2 , full weightbearing was not applied on the affected extremity when standing, and the extremity could not be used when walking. On postoperative day 90, cases 2 and 11 were observed with normal weightbearing when standing, and slight pressure when walking. In all the other cases, weightbearing when standing and walking was evaluated as equal to that of the normal extremity. When making the evaluations with this scale, the daily activity level of the cases was taken into consideration. When the intense exercise conditions of cases 1, 3, 5, 6, 8, and 9 were applied, the weightbearing of the extremities was not equal, as has been previously reported in literature, but the owners reported that this condition recovered after the dog had rested.

In motor control studies conducted on humans with CCL le- 


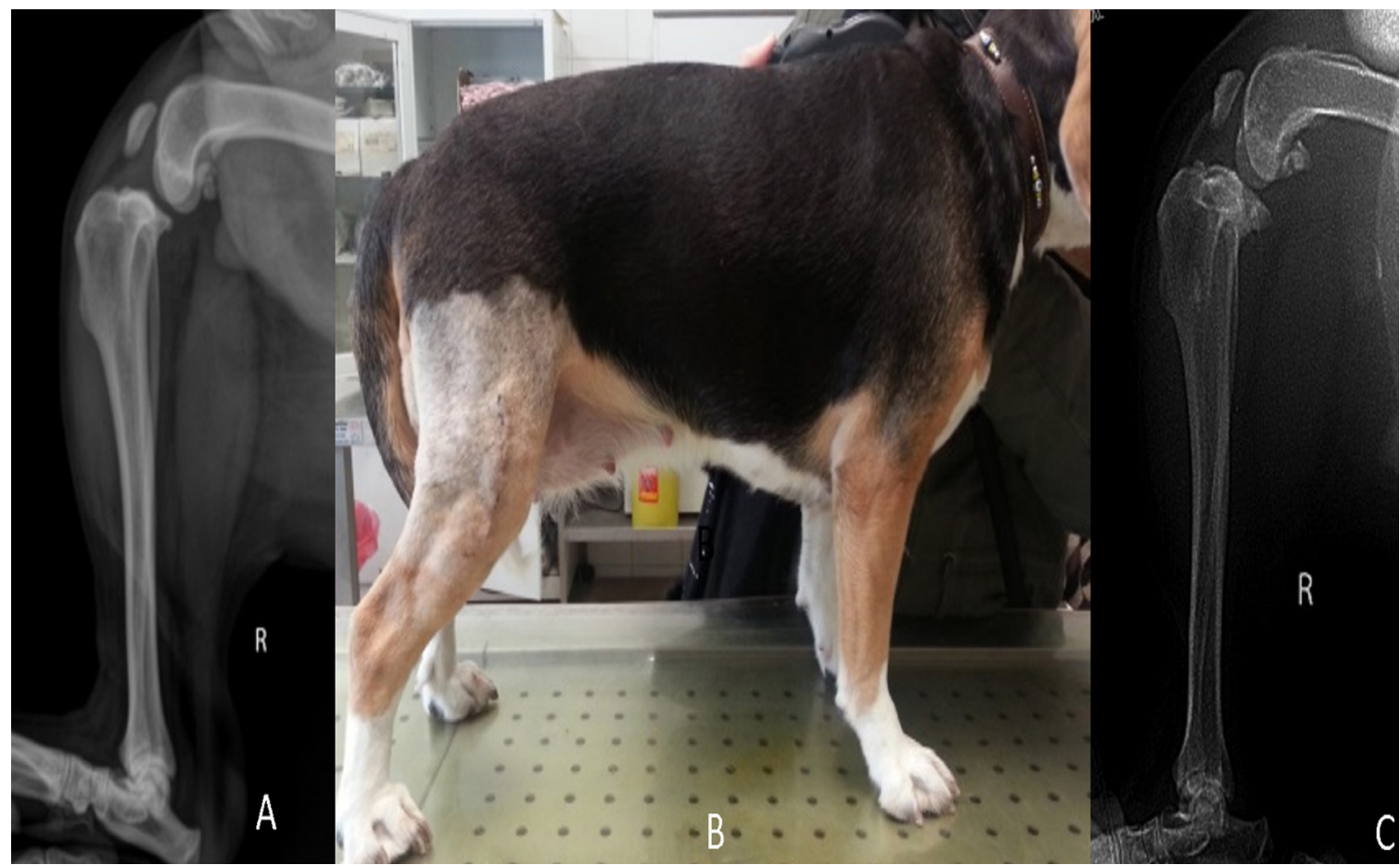

Figure 5. Radiographs and standing image of case no 9. A) Preoperative M/L radiograph, B) postoperative 10th day standing image, C) Postoperative 90th day $\mathrm{M} / \mathrm{L}$ radiograph.

sions, the effect of muscle activity has been discovered to have an important role in supporting joint structures and in preventing the recurrence of the lesion. Consequently, new methods have been developed to optimise muscle activation, and human physiotherapy applications have been improved and updated. Optimum motor control requires sensitive modulation of muscle activity. Effort must be made to provide co-ordination to perform controlled and functional movements. Specific muscle activation or the identification and modification of the motor control mechanism after CCL rupture in predisposed dogs may provide the opportunity to develop new ideas about the process of effective management of the lesion etiopathogenesis. The high impact and sudden changes occurring in weightbearing on the joint emerge as excessive tension which can be resisted by the ligament and meniscus. Therefore, additional support which could form resistance may be necessary for joint stabilisation. These additional support forms may be limited or prevented by soft tissue trauma. Muscle activation throughout joint movement plays a very important role in joint compression and joint stability. In the human musculoskeletal system, the muscle groups primarily responsible for joint stability when walking are the quadriceps and gastrocnemius muscles. To provide joint stability in dogs, the CCL, quadriceps, gastrocnemius and biceps femoris muscles must be co-ordinated with each other and must work at specific times during dynamic movements (19).

In the biceps femoris muscle transposition technique applied in this study, active contraction of this muscle prevents cranial translation of the tibia because of the caudal force formed with contraction. At the same time, because of the part of the body where the muscle is located, there is also a force in the lateral direction in addition to the caudal direction of the contraction force. Thus, the active movement prevents excessive internal rotation which occurs as a result of CCL rupture.

In a retrospective study, complication rates of procedures used in the treatment of cruciate ligament ruptures were examined. These included loosening of the screws used in the procedure, tibial tuberosity fracture, patella ligament inflammation, osteomyelitis, oedema in the distal part of the stifle joint, soft tissue infection, intra-articular migration or penetration of the screws used, and delayed healing. Several studies in literature have reported complications of extracapsular techniques at the rate of $<10 \%$. In a study in which 20 dogs were treated with the lateral retinacular fascia technique, swelling in the operation area observed for 2 days postoperatively was reported at the rate of $10 \%$, and reaction to the suture material associated with bacterial infection at $25 \%$. In the fibula head transposition technique, complications have been reported of lateral avulsion of the collateral ligament at $2.5 \%$, and fracture of the fibula head during pin application or transposition at $3.3 \%-12.5 \%$. Although iatrogenic damage to the peroneal nerve is very rare, the complication of the drawer eye movement test remaining positive has been reported at 6\%-16.7\% (20).

In the extracapsular technique of biceps femoris muscle transposition, which was applied in this study, the transposition was made at the closest possible point to the attachment point of the patella ligament to the tibial tuberosity. In all the cases in this study, the procedure was completed in approximately 20 mins, so the risk of bacterial infection was reduced to a minimum. Wound site reaction was seen on day 10 in only 2 (cases 1, 6) of the 14 dogs, and these were successfully treated. As the operating time is short and the technique is minimally invasive, a lower complication rate was observed in the current study than has been reported in literature.

In comparison with dogs weighing $<15 \mathrm{~kg}$ and those which can be treated conservatively, there is a need for surgical intervention in most dogs to provide joint stability and prevent the secondary development of osteoarthritis and meniscus lesions. When the results of the current study are examined, it can be seen that joint stabilisation was regained at the end of 
3 months with treatment using the biceps femoris muscle technique. Within the first month of follow-up, the general condition of all the dogs had improved and in the second month, the recovery process was completed.

The surgical procedure applied in this technique can be completed in a shorter time than other intra and extracapsular methods. The mean time for the application of this technique has been reported as 20 mins, and similar times were recorded for the operations in the current study. Therefore, the risk of postoperative infection has been seen to have been significantly reduced compared to other surgical procedures.

No arthrotomy was applied to any case and the currrent study population was small.

\section{CONCLUSION}

This study can be considered of guidance for further extracapsular studies which should include a larger population.

As the postoperative clinical data of this study were subjective, it can be recommended that gait analysis evaluations or video recordings are made of the dogs. The use of multimodal systems (kinetic, kinematic and electromyographic) of gait analysis and taking 3-dimensional measurements would overcome the limitations of the current study and provide more objective data.

The cases in the current study were followed up for 90 days in respect of the formation and progression of osteoarthritis and long-term complications. It can be recommended that future studies include a longer postoperative follow-up period in respect of postoperative complications.

\section{CONFLICTS of INTEREST}

The authors declare no conflicts of interest with respect to the publication of this manuscript.

\section{REFERENCES}

1. Guthrie JW, Keeley BJ, Maddock E, Bright SR, May C. Effect of signalment on the presentation of canine patients suffering from cranial cruciate ligament disease. J Small Anim Prac. 2012; 53(5): 273-277.

2. Piermattei DL. Handbook of Small Animal Orthopedics and Fracture Repair In: D.L. Piermattei, G.L. Flo, C.E. Decamp (Ed) The Stifle Joint. Philadelphia: Saunders; 2006. p. 562-632.

3. Rooster HD, Ryssen BV, Bree HV. Diagnosis of cranial cruciate ligament injury in dogs by tibial compression radiography. Vet Rec. 1998; 142: 366-368.

4. Rooster HD, De Bruin T, Van Bree H. Morphologic and Functional Features of the Canine Cruciate Ligaments. Vet Surg. 2006; 35(8): 769-780.

5. Hayashi K, Frank JD, Dubinsky C, Hao Z, Markel MD, Manley PA, Muir P. Histologic Changes in Ruptured Canine Cranial Cruciate Ligament. Vet Surg. 2003; 32(3): 269-277.

6. Infernuso T, Loughin CA, Marino DJ, Umbaugh SE, Solt PS. Thermal Imaging of Normal and Cranial Cruciate Ligament-Deficient Stifles in Dogs. Vet Surg. 2010; 39(4): 410-417.
7. Jerram RM, Walker AM. Cranial cruciate ligament ligament injury in the dog: pathophysiology, diagnosus and treatment. $\mathrm{N}$ Z Vet J. 2003; 51(4): 149-15.

8. Kim SE, Pozzi A, Kowaleski MP, Lewis DD. Tibial osteotomies for cranial ligament insufficiency in dogs. Vet Surg. 2008; 37(2): 111-125.

9. Sağlam M, Kaya Ü. Köpeklerde ön çapraz bağ kopmalar1nın sapaltımında modifiye intrakapsüler musculus tensor fasciae latae grefti uygulamas1. Ankara Üniv Vet Fak Derg. 2000; 47: $81-88$.

10. Kaya Ü. Küçük 1rk köpeklerde ön çapraz bağ kopmalarının ekstrakapsüler stabilizasyonunda fasial bant kullanımının klinik değerlendirmesi. Yüzüncü Y1l Üniv Vet Fak Derg. 2003; 14(1): 40-45.

11. Aslanbey D. Veteriner Ortopedi ve Travmatoloji Ders Kitab1. In: Köpeklerde çapraz bağ lezyonları. Ankara: Medisan Yay1n Serisi; 1994. p. 98-111.

12. Fossum TW. Small Animal Surgery. In: Disease of the joints. 4th Ed. St. Louis: Mosby Inc; 2012. p. 1323-1343.

13. Slatter D. Textbook of Small Animal Surgery. In: Vasseur PB (Ed) Stifle Joint. 3rd Ed. Philadelphia: Elsevier; 2003. p. 2090-2118.

14. Bumin A, Kaya Ü, Temizsoylu MD, Kibar M, Alkan Z, Sağlam M. The clinical, radiographical and arthroscopical diagnosis of cranial cruciate ligament lessions and surgical therapy in dogs. Turk J Vet Anim Sci. 2002; 26(2): 397-401.

15. Aragon CL, Budsberg SC. Applications of evidence-based medicine: cranial cruciate ligament injury repair in the dog. Vet Surg. 2005; 34(2): 93-98.

16. Conzemius MG, Evans RB, Besancon MF, Gordon WJ., Horstman CL, Hoefle WD, Nieves MA, Wagner SD. Effect of surgical technique on limb function after surgery for rupture of the cranial cruciate ligament in dogs. J Am Vet Med Assoc. 2005; 226(2): 232-236.

17. Tamburro R, Pinna S, Tribuiani AM, Panacea A, Carli F, Venturini A. Biceps femoris muscle transposition for treatment of cranial cruciate ligament rupture in small breed dogs. J Vet Sci. 2012; 13(1): 93-98.

18. Snow LA, White R, Gustafson S, Xie L, Hosgood G, Monroe W, Casey JP, Lopez MJ. Ex vivo comparison of three surgical techniques to stabilize canine cranial cruciate ligament deficient stifles. Vet Surg. 2010; 39(2): 195-207.

19. Adrian CP, Haussler KK, Kawcak C, Reiser RF, Krugh CR, Palmer RH, Mcllwraith CW, Taylor RA. The role of muscle activation in cruciate disease. Vet Surg. 2013; 42(7): 765-773.

20. Pacchiana PD, Morris E, Gillings SL, Jessen CR, Lipowitz AJ. Surgical and postoperative complications associated with tibial plateau leveling osteotomy in dogs with cranial cruciate ligament rupture: 397 cases (1998-2001). J Am Vet Med Assoc. 2003; 222(2): 184-193. 